\title{
Left ventricular preload reserve in preterm infants with patent ductus arteriosus
}

\author{
Yasushi Takahashi, Kenji Harada, Akira Ishida, Masamichi Tamura, Goro Takada
}

\begin{abstract}
The left ventricular Frank-Starling response was studied in 15 preterm infants, less than $1500 \mathrm{~g}$ birth weight, and in 16 fullterm infants with patent ductus arteriosus. Left ventricular end diastolic volume (LVEDV), stroke volume, and cardiac output were calculated from biplane echocardiographic images with a modified Simpson's rule, and the left ventricular function curve was obtained by standardising with birth weight and body length. In the relationship between LVEDV and stroke volume, the slope of the regression line was significantly milder in preterm than in fullterm infants; however, there was no significant difference in the relationship between LVEDV and cardiac output. The heart rate was significantly higher in preterm than in fullterm infants. Our data indicated that the premature infants had less left ventricular reserve capacity to respond to the increased preload through the left-to-right ductal shunting than the mature ones, and that the high pulse rate made it possible to generate adequate cardiac output in premature infants.

(Arch Dis Child 1994; 71: F118-F121)
\end{abstract}

During the transitional change from fetal to neonatal circulation, the presence of a patent ductus arteriosus (PDA) and a left-to-right ductal shunting adversely affects the cardiopulmonary status of preterm infants as an increase of preload for the left ventricle. ${ }^{12}$ Animal research on lambs has shown that the premature lamb has less preload reserve capacity in the left ventricle to respond to volume loading than the mature lamb, ${ }^{3-6}$ but this fact has not been fully investigated in human premature neonates. Using echocardiographic techniques, we have studied the Frank-Starling relationship of the left ventricle in preterm $(<1500 \mathrm{~g}$ birth weight $)$ and full-

Table 1 Patient characteristics at the echocardiographic examinations; values are mean (range)

\begin{tabular}{|c|c|c|}
\hline & Preterm infants $(n=15)$ & fullterm infants $(n=16)$ \\
\hline Gestational age (weeks) & $29(24-32)$ & $39(37-41)$ \\
\hline Birth weight $(\mathrm{g})$ & $1093(732-1496)$ & $3107(2694-3742)$ \\
\hline Body length $(\mathrm{cm})$ & $35.9(32 \cdot 0-40 \cdot 0)$ & $49 \cdot 6(48 \cdot 0-51 \cdot 0)$ \\
\hline Peripheral skin temperature $\left({ }^{\circ} \mathrm{C}\right)$ & $37 \cdot 0(36 \cdot 4-37 \cdot 7)$ & $36.9(36 \cdot 8-37.4)$ \\
\hline \multicolumn{3}{|l|}{ Blood pressure (mm Hg) } \\
\hline $\begin{array}{l}\text { Systolic } \\
\text { Diastolic }\end{array}$ & $46(35-58)$ & $59(45-74)$ \\
\hline Diastolic ${ }^{\star}$ & $26(18-36)$ & $34(26-41)$ \\
\hline \multicolumn{3}{|l|}{ Blood pH } \\
\hline Artery $(n=8)$ & $7 \cdot 463(7 \cdot 368-7 \cdot 532)$ & Not measured \\
\hline Vein $(n=7)$ & $7 \cdot 377(7 \cdot 304-7 \cdot 512)$ & Not measured \\
\hline
\end{tabular}

${ }^{\star} \mathrm{p}<0.05$ compared preterm with fullterm infants by unpaired $t$ test. term infants with PDA. The purpose of this study was to compare the left ventricular preload reserve capacity of premature infants with that of mature ones, and to investigate the mechanism of cardiovascular adaptation in premature infants with PDA.

\section{Subjects and methods} SUBJECTS

We studied 16 fullterm and 15 preterm infants. The patient characteristics are summarised in table 1 . The mean gestational age at birth was 39 weeks in fullterm infants and 29 weeks in preterm infants. The mean birth weight was $3107 \mathrm{~g}$ in fullterm infants and $1093 \mathrm{~g}$ in preterm infants, and the mean body length was 49.6 and $35.9 \mathrm{~cm}$, respectively. All fullterm infants had a history of normal pregnancy and delivery, and had no symptoms of systemic or cardiovascular diseases on physical examination. All preterm infants were admitted to the neonatal intensive care unit in Akita University Medical Hospital. They had no severe asphyxia (mean Apgar score: 6 at one minute, 8 at five minutes after birth) and clinical signs of shock at birth, and underwent intubation and ventilation with a pressure controlled ventilator. Three preterm infants had clinical signs of respiratory distress syndrome, but improved on synthetic surfactant replacement treatment.

Informed consent was obtained from the parents of each neonate.

PROTOCOL

We performed echocardiographic examinations within six hours after birth: mean time was 3.6 hours in fullterm infants and 3.8 hours in preterm infants. During the examinations, all fullterm infants were in a non-sedated resting state, and the preterm infants were having treatment with intravenous fluid $35-45 \mathrm{ml} / \mathrm{kg} /$ day of $10 \%$ glucose solution that included $20-40 \mathrm{mg} / \mathrm{kg} /$ day of calcium without inotropic agents. To assess whether systemic resistance is constant at the echocardiographic examinations, we measured steady peripheral skin temperature and blood pressure in both fullterm and preterm infants, and additionally the arterial or venous blood $\mathrm{pH}$ in preterm infants (table 1 ). The peripheral skin temperature did not differ significantly between fullterm and preterm infants, but both the systolic and diastolic blood pressures, obtained from a Dinamap 8100 Vital Sign Monitor, were lower in preterm infants than in fullterm ones $(p<0 \cdot 05)$. The blood samples were obtained from umbilical artery or vein in 
A

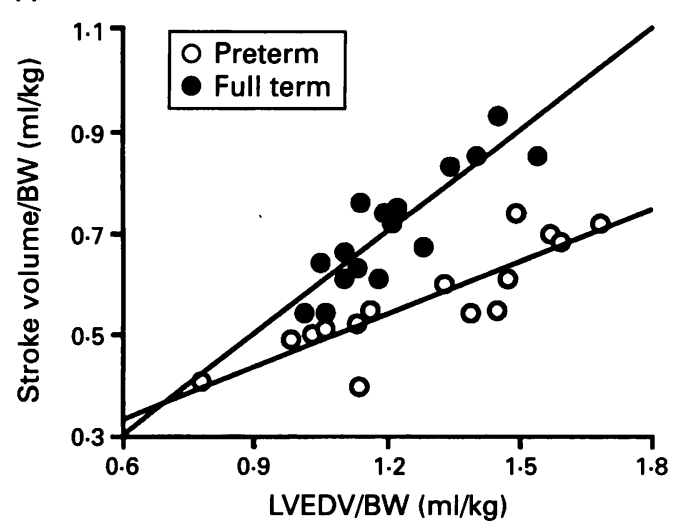

C

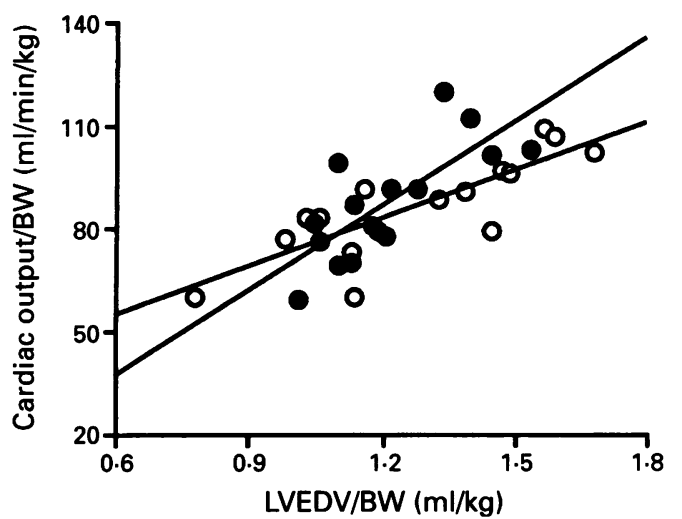

B

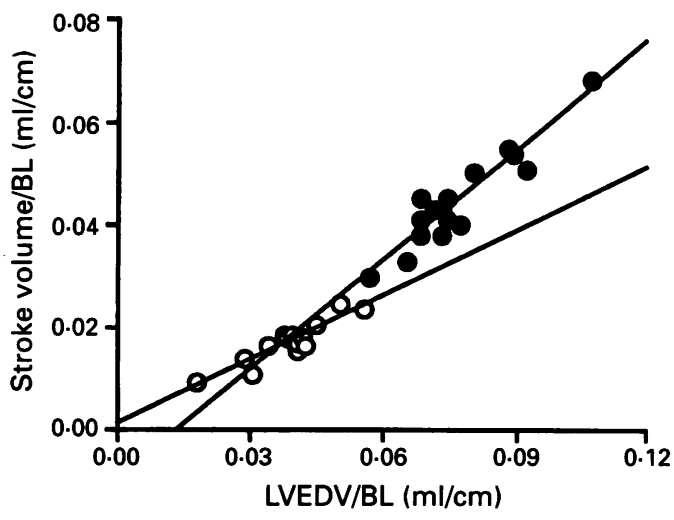

D

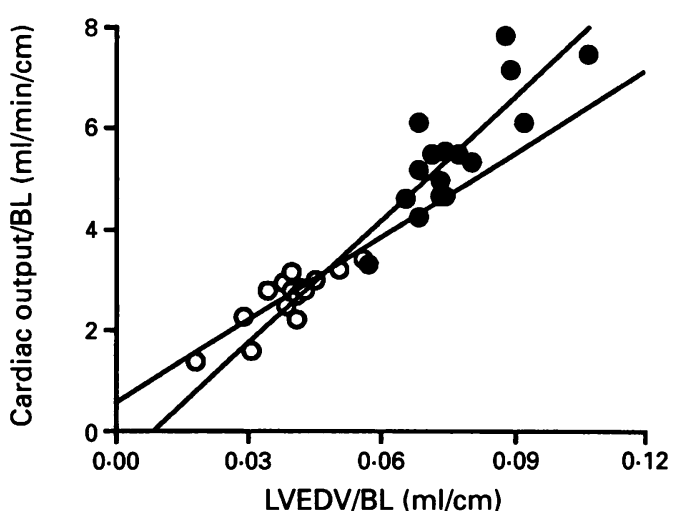

(A) Relationship between the $L V E D V / B W$ and the stroke volume/BW in the preterm and fullterm infants with $P D A ;(B)$ that between the $L V E D V / B L$ and the stroke volume/BL; (C) that between the $L V E D V / B W$ and the cardiac output/BW; and (D) that between the LVEDV/BL and the cardiac output/BL.

preterm infants, and blood $\mathrm{pH}$ was measured using an AVL947 blood gas analyser. The mean values of arterial or venous blood $\mathrm{pH}$ were $7 \cdot 463$ and $7 \cdot 377$, respectively, and they did not apparently differ from those of fullterm infants described previously. ${ }^{7}$

\section{ECHOCARDIOGRAPHY}

We performed echocardiographic examinations by two dimensional pulsed Doppler and two dimensional colour Doppler. An Aloka SSD-870 ultrasound imaging system equipped with a $5.0 \mathrm{MHz}$ pencil type transducer was used. Initially, we confirmed the absence of congenital heart disease and the patency of the ductus arteriosus with the left-to-right high velocity jet stream by these two methods. All the subsequent echocardiographic measurements were performed according to the recommendations of the American Society of Echocardiography, ${ }^{8}$ and the averaged data from 3-5 cardiac cycles were used for analysis.

The standard apical two and four chamber views were used for analysis of left ventricular volume. Using an off-line computed digitiser (Cardio 500, Kontron Medical System), we calculated left ventricular end diastolic volume (LVEDV) and left ventricular end systolic volume (LVESV) by a modified Simpson's rule method; in addition, heart rates were obtained simultaneously. To compare the values of preterm infants with those of fullterm ones, the
LVEDV and LVESV measurements were divided by birth weight (BW) and body length (BL) in each infant. Then the following variables were obtained: (1) LVEDV/BW $(\mathrm{ml} / \mathrm{kg})$; (2) LVEDV/BL (ml/cm); (3) stroke volume/BW $(\mathrm{ml} / \mathrm{kg})=[\mathrm{LVEDV}-\mathrm{LVESV}] / \mathrm{BW} ;$ (4) stroke volume/BL $(\mathrm{ml} / \mathrm{cm})=[\mathrm{LVEDV}-\mathrm{LVESV}] / \mathrm{BL}$; (5) cardiac output/BW $(\mathrm{ml} / \mathrm{min} / \mathrm{kg})=$ heart rate $\times[\mathrm{LVEDV}-\mathrm{LVESV}] / \mathrm{BW}$; (6) cardiac out$\mathrm{put} / \mathrm{BL}(\mathrm{ml} / \mathrm{min} / \mathrm{cm})=$ heart rate $\times[\mathrm{LVEDV}-$ LVESV]/BL; (7) ejection fraction=LVEDVLVESV]/LVEDV. Finally, we obtained the relationships between LVEDV and stroke volume and that between LVEDV and cardiac output, which were standardised with birth weight and body length.

\section{INTEROBSERVER AND INTRAOBSERVER}

\section{VARIABILITY}

Interobserver and intraobserver variability were assessed for the left ventricular volume calculations over five cardiac cycles in five randomly selected subjects. The variability was determined as a mean per cent error, derived as the absolute difference between two observations divided by the mean of the two observations and expressed in per cent.

\section{STATISTICAL ANALYSIS}

The normality of the distribution of each parameter was initially confirmed. To standardise the measurements with birth weight 
and body length, we confirmed the close relationship between birth weight and LVEDV, stroke volume, and cardiac output, as well as that between body length and those parameters, in both fullterm and preterm infants. A simple linear regression analysis was used to determine the significance of the correlation between LVEDV and stroke volume, and that between LVEDV and cardiac output. An analysis of covariance was used to determine the significance of the distribution difference between preterm and fullterm infants. For comparison of data, the unpaired $t$ test was used, and $p \leqslant 0.05$ was considered to indicate statistical significance. All values were expressed as the mean (SD).

\section{Results}

ECHOCARDIOGRAPHIC DATA AND CHANGE OF HEART RATE

The findings are summarised in table 2 . The LVEDV, stroke volume, and cardiac output were significantly lower in preterm infants as expected. The ejection fraction was also significantly lower in preterm infants than in fullterm ones; however, the heart rate was significantly higher in preterm infants.

RELATIONSHIP BETWEEN LVEDV AND STROKE VOLUME AND BETWEEN LVEDV AND CARDIAC OUTPUT

The relationships are shown in the figure. There was a linear correlation between the LVEDV/BW and the stroke volume/BW in both preterm and fullterm infants (figure A); preterm infants: (stroke volume/BW) $=0.35$ $(\mathrm{LVEDV} / \mathrm{BW})+0 \cdot 12, r=0 \cdot 87, \mathrm{p}<0.001$; fullterm infants: (stroke volume/BW) $=0.67$ (LVEDV/BW) $-0.11, \quad r=0.88, \quad \mathrm{p}<0.001$. Similarly, there was a linear correlation between the LVEDV/BL and the stroke volume/BL (figure $\mathrm{B}$ ); 'preterm infants: (stroke volume/BL) $=0.42(\mathrm{LVEDV} / \mathrm{BL})+0.01$, $r=0.91, \mathrm{p}<0.001$; fullterm infants: (stroke volume $/ \mathrm{BL})=0.72 \quad(\mathrm{LVEDV} / \mathrm{BL})-0.01, \quad r=$ $0.94, \mathrm{p}<0.001$. In comparison between preterm and fullterm infants, the distribution of values was significantly different in both relationships by analysis of covariance; in addition, the slope of the regression line was significantly milder in preterm infants than in fullterm ones.

There was also a linear correlation between the LVEDV/BW and the cardiac output/BW in both preterm and fullterm infants (figure $C$ ); preterm infants: (cardiac output $/ \mathrm{BW}$ ) $=47 \cdot 0$ $(\mathrm{LVEDV} / \mathrm{BW})+26 \cdot 2, \quad r=0 \cdot 81, \mathrm{p}<0 \cdot 001$; full-

Table 2 Echocardiographic results and the change of heart rate; values are mean $(S D)$

\begin{tabular}{lcc}
\hline & $\begin{array}{c}\text { Preterm infants } \\
(n=15)\end{array}$ & $\begin{array}{l}\text { Fulterm infants } \\
(n=16)\end{array}$ \\
\hline LVEDV (ml) & $1.40(0 \cdot 36)^{\star}$ & $3 \cdot 79(0 \cdot 65)$ \\
Stroke volume $(\mathrm{ml})$ & $0 \cdot 62(0 \cdot 17)^{\star}$ & $2 \cdot 22(0 \cdot 50)$ \\
Cardiac output $(\mathrm{ml} / \mathrm{min})$ & $94 \cdot 7(24 \cdot 4)^{\star}$ & $274 \cdot 1(64 \cdot 3)$ \\
Ejection fraction & $0 \cdot 45(0 \cdot 05)^{\star}$ & $0.58(0.05)$ \\
Heart rate $(/ \mathrm{min})$ & $152(11)^{\star}$ & $123(14)$ \\
\hline
\end{tabular}

${ }^{\star} \mathrm{p}<0.001$. term infants: (cardiac output/BW) $=82 \cdot 4$ (LVEDV/BW) $-12 \cdot 6, \quad r=0.76, \quad \mathrm{p}<0.001$, as well as the relationship between the LVEDV/BL and the cardiac output/BL (figure D); preterm infants: (cardiac output/BL) $=0.42$ (LVEDV/BL) +0.01, $r=0.91, \mathrm{p}<0.001$; fullterm infants: (cardiac output/BL) $=0.72$ (LVEDV/BL) $-0.01, \quad r=0.94, p<0.001$. In comparison between preterm and fullterm infants, in contrast to the relationship between the LVEDV and the stroke volume, there was no significant difference in the distribution and the slope of the regression line.

\section{INTEROBSERVER AND INTRAOBSERVER}

VARIABILITY

The coefficient of variation for interobserver and intraobserver variability for the left ventricular volume calculations was $0 \cdot 3-7 \cdot 6 \%$ and $0 \cdot 2-6 \cdot 1 \%$, respectively.

\section{Discussion}

The present study showed that premature infants had less reserve capacity in the left ventricle to respond to the increased preload through the left-to-right ductus arteriosus shunting than the mature ones; however, the increased heart rate in the premature infants compensated for their low left ventricular stroke volume and made it possible to generate the adequate left ventricular output.

The previous Doppler echocardiographic studies well demonstrated the left-to-right ductus arteriosus shunting and its effect as an increase of left ventricular preload. ${ }^{9} 10$ As the index of this increased preload, we divided LVEDV by both birth weight and body length instead of body surface area usually used in older children, because it is difficult to measure accurately the body surface area of premature infants, especially those less than $1500 \mathrm{~g}$ at birth. A previous investigator divided the volumetric measurements of preterm infants by birth weight for adjustment, ${ }^{9}$ while another described that adjustment only with body weight may be misleading. ${ }^{11}$ Thus we divided LVEDV and other measurements not only by birth weight but also by body length to confirm the conclusion. In the present study we calculated LVEDV by the biplane Simpson's rule geometric method, because it is more accurate to estimate neonatal left ventricular volume with distortion due to the relatively high right ventricular pressure after birth ${ }^{12} 13$ than an area/length or $\boldsymbol{M}$ mode determined volume calculation method. As far as we know, there are few reports estimating LVEDV in human premature and mature neonates by a biplane echocardiographic images with a modified Simpson's rule.

In the relationship between the LVEDV and the stroke volume, the slope of the regression line was significantly milder in preterm than in fullterm infants (figure A, B), and the left ventricular ejection fraction was also significantly lower in preterm than in fullterm infants. These findings, indicating that premature infants had less capacity to generate adequate 
left ventricular stroke volume in proportion to the quantity of the left-to-right ductal shunting than the mature infants, were consistent with the previous reports of the Frank-Starling relationships on fetal and neonatal lambs. ${ }^{14-16}$ We could not observe the 'plateau limb' of the Frank-Starling curve as reported in animal research. ${ }^{14-16}$ This may be because of the difference between the artificial and natural volume loading. In contrast to the relationship between LVEDV and stroke volume, there was no significant difference between preterm and fullterm infants in the relationship between LVEDV and cardiac output, indicating that the high pulse rate compensated for the low left ventricular stroke volume in the premature infants.

It is necessary to assess the afterload, in addition to the preload, to investigate left ventricular contractile state in preterm and fullterm infants. We have measured the steady peripheral skin temperature, blood $\mathrm{pH}$, and blood pressure, which mainly influence systemic resistance. There seemed to be no apparent difference in the steady peripheral skin temperature and blood $\mathrm{pH}$ between preterm and fullterm infants, however, the blood pressure in the preterm infants was significantly lower than that in the fullterm ones. In animal research on preterm lambs Clyman et al hypothesised that the reduced left ventricular afterload plays an important part to increase its stroke volume when challenged with PDA. ${ }^{6}$ In the present study the preterm infants with PDA showed less capacity to generate stroke volume even under the lower blood pressure.

We have confirmed that a high pulse rate is necessary for the cardiovascular adaptation in premature infants with PDA, and that a careless use of plasma volume expander or bradycardia may result in the failure of maintaining adequate left ventricular output in the premature infants. This study has hopefully provided useful basic data concerning the left ventricular contractile state in premature and mature infants with PDA.

We thank Dr Takashi Suzuki for his help to the statistical analysis.

1 Johnson GL, Breart GL, Gewitz MH, et al. Echocardiographic characteristics of premature infants with patent ductus arteriosus. Pediatrics 1983; 72: 864-71.

2 Kitterman JA, Edmunds LH, Gregory GA, Heymann MA, Tooley WH, Rudolph AM. Patent ductus arteriosus in premature infants - incidence, relation to pulmonary disease and management. $N$ Engl $\mathcal{f}$ Med 1972; 287: 473-7.

3 Baylen BG, Ogata $H$, Ikegami $M$, Jacobs $H$, Jobe $A$, Emmanoulides GC. Left ventricular performance and contractility before and after volume infusion: a comparacontractility before and after volume infusion: a comparative study of preterm and
Circulation 1986; 73: 1042-9.

4 Baylen BG, Ogata $\mathrm{H}$, Oguchi $\dot{K}$, et al. The contractility and performance of the preterm left ventricle before and after early patent ductus arteriosus occlusion in surfactant treated lambs. Pediatr Res 1985; 19: 1053-8.

5 Friedman WF. The intrinsic physiologic properties of the developing heart. Prog Cardiovasc Dis 1972; 15: 87-111.

6 Clyman RI, Roman C, Heymann MA, Mauray F. How a patent ductus arteriosus affects the premature lamb's ability to handle additional volume loads. Pediatr Res 1987; 22: 531-5.

7 Weisbrot IM, James LS, Prince CE, Holaday DA, Apgar V. Acid-base homeostasis of the newborn infant during the Acid-base homeostasis of the newborn infant during

8 Schiller NB, Shah PM, Crawford M, et al. Recommendations for quantitation of the left ventricle by two dimensional echocardiography: American Society of Echocardiography committee on standards subcommittee. F Am Soc Echocardiogr 1989; 2: 358-67.

9 Drayton MR, Skidmore R. Ductus arteriosus blood flow during first 48 hours of life. Arch Dis Child 1987; 62: $1030-4$.

10 Agata Y, Hiraishi S, Oguchi K, et al. Changes in left ventricular output from fetal to early neonatal life. f Pediatr 1991; 119: 441-5.

11 Tanner JM. Fallacy of per-weight and per-surface area standards, and their relation to spurious correlation. standards, and their relation

12 Azancot A, Caudell TP, Allen HD, et al. Analysis of ventricular shape by echocardiography in normal fetuses, newborns, and infants. Circulation 1983; 68: 1201-11.

13 Lee LA, Kimball TR, Daniels SR, Khoury P, Meyer RA. Left ventricular mechanics in the preterm infant and their effect on the measurement of cardiac performance. f Pediatr 1992; 120: 114-9.

14 Romero T, Covell J, Friedman WF. A comparison of pressure-volume relations of the fetal, newborn, and adult heart. Am F Physiol 1972; 222: 1285-90.

15 Kirkpatrick SE, Pitlick PT, Naliboff J, Friedman WF. Frank-Starling relationships as an important determinant Frank-Starling relationships as an important determinant
of fetal cardiac output. Am $\mathcal{F}$ Physiol 1976; 231: 495-500.

16 Grant DA, Maloney JE, Tyberg JV, Walker AM. Effects of Grant DA, Maloney JE, Tyberg J W W wentricular function

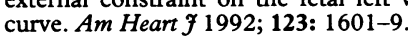

